\title{
E.E.G. studies in the syndrome of isolated episodes of confusion with amnesia 'transient global amnesia'
}

\author{
R. JAFFE AND M. B. BENDER \\ From the Department of Neurology, The Mount Sinai Hospital, New York, U.S.A.
}

The syndrome of an isolated episode of confusion with amnesia is actually not uncommon, occurring from time to time in the practice of every neurologist and psychiatrist. Like Poe's purloined letter, however, it stands disguised by a group of similar, though demonstrably different entities. Bender was the first to describe this syndrome (Bender, 1956, 1960), and it was independently reported two years later by Fisher and Adams (Fisher and Adams, 1958, 1964). Bender called it 'single episode of confusion with amnesia', Fisher and Adams 'transient global amnesia'.

The characteristic feature of this syndrome is the occurrence, in a middle-aged person (usually in the sixth decade), of a single episode of confusion, with permanent amnesia for the period of the episode. The episodes most commonly occur in persons without prior evidence of cerebral dysfunction, begin suddenly, last for two to 12 hours, gradually clearing or disappearing during sleep. The most prominent behavioural characteristics are restlessness, anxiety, and a confusional state marked by almost complete loss of retention. There may be retrograde amnesia for events of the preceding hours or days, but the patient is aware of his own identity, and usually knows where he is. Statements such as 'what's happening to me-I must be losing my mind', 'I'm cracking up', or 'what is going on?' are common. The patient typically asks the same question repeatedly, often in reference to some family matter or a question of orientation. 'When is Louise's party?' or 'what day is it today?' may be said again and again. The patient becomes upset if the questions are not answered, but does not retain the answers for more than a few seconds if they are given. The grammar, syntax, and vocabulary of spontaneous speech are not disturbed. Object naming is intact. There are no focal disturbances in motor, sensory, or visual function. Simple calculations and reverse spelling may be well performed at a time when

${ }^{1}$ Assisted by U.S.P.H.S. grant N.B 05221. retention of new data may be limited to 80 to 100 seconds.

There are many possible variations in the behaviour pattern during the episode. The patient may in some cases be quite lost and helpless; in other cases some actions may be efficiently carried out, such as setting out for and driving to an appropriate destination. In some cases, the degree of confusion may be so severe as to be immediately apparent to others. In other cases the witnesses recall, only after questioning, that the patient was 'not his usual self', was peculiarly querulous and repetitious. In one recent instance the patient piloted his 28-foot cruiser through several hours of fishing and was amnesic for the entire trip. He was observed by his companions only to be making occasional apparently irrelevant statements, such as 'are you sure we have enough gas?' and 'what part of Long Island Sound are we in?' Since he was functioning as if he really knew the answers to these questions, the questions were ignored.

The period of intense confusion may last for one to six hours, and as the patient begins to recover, the retention improves, and the anxiety lessens. Following the episode, there is complete amnesia, except for the period at the end, where some retention was observed during the episode. The amnesia is limited to this episode itself, however, and the retrograde amnesia observed during the episode disappears.

Another cardinal feature of the syndrome is that the episode of confusion is characteristically unique. There are no premonitory signs and no sequelae. Certain individuals have been followed for periods as long as 10 and 15 years without showing any evidence of recurrence, or any other signs of cerebral dysfunction. Rare patients have had more than one episode, but in all other respects the syndrome is typical. None of these, however, have given evidence of progressive brain disease.

Fifty-one patients showing this syndrome have been examined, 10 during the episode. The E.E.G.s were performed in 27 of the 51 patients. In five 
instances the E.E.G. was done during the period of confusion. All but one of the patients tested had normal E.E.G.s. Some of the tracings, as might well be expected in the 50-65 age group, were of the lowvoltage fast variety, but most had a prominent regular alpha rhythm, even during the episode. No unusual responses to hyperventilation or photic stimulation were noted. One patient, a 50-year-old woman, had occasional bursts of irregular 3-5 c/s activity in temporal derivations on the left side alone, or bilaterally, left more than right. These patterns were present during the episode and on recordings five days and seven months later. In 24 months of follow-up she showed no clinical evidence of recurrence or active disease of the central nervous system.

As a clinical phenomenon, the mental disturbance seen in this syndrome closely approximates that seen in many cases of loss of memory due to alcohol, in cases of head trauma, and in rare instances of brain tumour or viral encephalitis. The paradoxical coexistence of severe retention defects and retrograde amnesia, with fairly well-preserved remote memory and immediate comprehension, is characteristic of all these conditions (Victor and Yakovlev, 1955; Rose and Symonds, 1960; Williams and Pennybacker, 1954). The critical distinction which separates this syndrome described by one of us from those others, however, is its essentially benign, transient character, and its unique or very rare occurrence.

Somewhat similar phenomena may occur, episodically, in convulsive disorder patients. Patients with prolonged ictal automatisms ('psychomotor status') may be only partly confused and therefore may be able to function during the attack, and may be partly or completely amnesic afterwards (Strauss, 1959). This condition, however, usually starts at an early age, is typically repetitive, and usually is seen in patients who have had other convulsive phenomena. The seizure patients are also free of the anxiety which is so prominent a feature of the syndrome of an isolated episode of confusion with amnesia. The E.E.G. during an ictal automatism is almost always abnormal and the inter-seizure record may also show abnormalities of the 'convulsive' type. It is true that focal motor seizures and brief automatisms may occur without demonstrable abnormality in the scalp E.E.G. This is rarely, if ever, the case with prolonged automatisms.

One other mechanism which comes to mind in relation to convulsive disorder is that the episode may represent a postconvulsive confusional state. These do occur and may be quite intense and prolonged. The history of convulsions is usually unequivocal, however, and this condition is also characteristically repetitive. These patients are quite likely to show abnormal inter-seizure E.E.G.s of the con- vulsive type, even though the E.E.G. may be normal during the period of post-ictal confusion.

Another possible mechanism for the dysfunction seen in this condition is transient vascular insufficiency. Any episode so abrupt in onset must be considered as being possibly of vascular origin. The problem presented by this hypothesis is: Which single blood vessel could be responsible? Which cerebral structure or system could be temporarily inactivated, or disturbed in function, and produce such a marked behaviour change, without E.E.G. abnormality, abnormality of the cerebrospinal fluid, focal signs, or sequelae.

In many cases the condition is rationalized by the physician who sees it as an hysterical dissociation state. Even experienced psychiatrists, when given a history of such an episode occurring in an anxious middle-aged woman, are prone to overlook the organic aspects of the behaviour disturbance. On closer inspection, however, the clinical distinctions between this condition and hysterical or schizophrenic dissociation states are so numerous as to make it obvious that the conditions are entirely different. The age incidence, negative prior history, anxiety, permanent amnesia, and isolated occurrence are only some of the typical features of this condition which are inconsistent with hysteria or schizophrenia.

There is a great convergence of data from neurosurgical and neuropathological sources (Barbizet, 1963; Penfield and Milner, 1958; Scoville and Milner, 1957; de Ajuriaguerra, Hécaen, and Sadoun, 1954; Lashley, 1950) which implicate the hypothalamic region, mammillary bodies, fornix, and hippocampus, in cases showing mental disturbances primarily characterized by defects in retention ('defect in memorizing, amnésia de mémoration'). Without asserting that these structures are the locus of 'memory', or even 'registration', it is possible to say that disease affecting them may severely impair, or destroy registration and memory. It seems reasonable to formulate the hypothesis that a transient episode, with a cardinal feature of severe retention defects, may involve transient dysfunction of the same anatomical complex. The observation of normal E.E.G.s in our cases tends to support this hypothesis. Transient diffuse cerebral dysfunction, whether due to epileptic, vascular, or toxic-metabolic mechanisms, is almost certain to be manifested by an abnormal E.E.G. Dysfunction in the deep rhinencephalic structures, however, may very well be unaccompanied by any detectable abnormality in scalp electrode tracings.

\section{SUMMARY}

A syndrome has been described which consists of 
the isolated occurrence, in a middle-aged person, of an episode of confusion and anxiety with conspicuous loss of retention, and amnesia for the entire episode. The hypothesis is presented that the episode is due to dysfunction in a portion of the rhinencephalon, and the characteristically normal E.E.G. is taken as evidence to support this hypothesis.

\section{REFERENCES}

Ajuriaguerra, J. de, Hécaen, H., and Sadoun, R. (1954). Les troubles mentaux au cours des tumeurs de la région méso-diencéphalique. Encéphale, 43, 406-478.

Barbizet, J. (1963). Defect of memorizing of hippocampal-mammillary origin: a review. J. Neurol. Neurosurg. Psychiat., 26, 127-135.

Bender, M. B. (1956). Syndrome of isolated episode of confusion with amnesia. J. Hillside Hosp., 5, 212-215.

(1960). Single episode of confusion with amnesia. Bull. N.Y Acad. Med., 36, 197-207.

Fisher, C. M., and Adams, R. D. (1958). Transient global amnesia. Trans. Amer. neurol. Ass., 83, 143-146.
(1964). Transient global amnesia. Acta neurol. scand., 40, suppl. 9.

Lashley, K. S. (1950). In search of the engram. In Physiological Mechanisms in Animal Behaviour, pp. 454-482. (Symp. Soc. $\exp$ Biol., No. IV.)

Penfield, W., and Milner, B. (1958). Memory deficit produced by bilateral lesions in the hippocampal zone. Arch. Neurol. Psychiat. (Chic.), 79, 475-497.

Rose, F. C., and Symonds, C. P. (1960). Persistent memory defect following encephalitis. Brain, 83, 195-212.

Scoville, W. B., and Milner, B. (1957). Loss of recent memory after bilateral hippocampal lesions. J. Neurol. Neurosurg. Psychiat., 20, 11-21.

Strauss, H. (1959). Epileptic disorders. American Handbook of Psychiatry, vol. 2, pp. 1109-1143. Edited by S. Arieti. Basic Books, New York.

Victor, M., and Yakovlev, P. I. (1955). S.S. Korsakoff's Psychic disorder in conjunction with peripheral neuritis. A translation of Korsakoff's original article, with brief comments on the author and his contribution to clinical medicine. Neurology (Minneap.), 5, 394-406.

Williams, M., and Pennybacker, J. (1954). Memory disturbances in third ventricle tumours. J. Neurol. Neurosurg. Psychiat., 17. 115-123. 